ISSN: 2165-8714

http://www.eu-jer.com/

\title{
Communication and Group Work in the Multicultural Classroom: Immigrant Students' Experiences
}

\author{
Artem Ingmar Benediktsson * \\ University of Iceland, ICELAND
}

\author{
Hanna Ragnarsdottir \\ University of Iceland, ICELAND
}

Received: January 8, 2019 - Revised: February 9, 2019 - Accepted: February 19, 2019

\begin{abstract}
The paper is part of the qualitative research project Educational Aspirations, Opportunities and Challenges for Immigrants in University Education in Iceland, conducted in Iceland's three biggest universities. The main goal of the paper is to investigate immigrant students' experiences of communication with teachers during the learning process and their perspectives on multicultural group work. Furthermore, the paper explores immigrant students' experiences of learner-centred approach and culturally responsive teaching methods applied by some teachers. The data was collected through focus group interviews and qualitative, semi-structured individual interviews with immigrant students. The theoretical framework is mainly based on the constructivist theory, which emphasises the importance of communication and the learner-centred approach. Additionally, the theoretical framework includes multicultural education theory, which puts an emphasis on applying culturally responsive teaching methods in classrooms with diverse student populations. The analysis of the interviews revealed that the participants' experiences of communication with teachers and peers were mostly positive. However, culturally responsive teaching is still a rare phenomenon in Icelandic universities. When it comes to the participants' perspectives on group work, the experiences ranged from being highly positive to negative.
\end{abstract}

Keywords: Communication, group work, immigrant students, higher education, Iceland.

To cite this article: Benediktsson, A. I., \& Ragnarsdottir, H. (2019). Communication and group work in the multicultural classroom: immigrant students' experiences. European Journal of Educational Research, 8(2), 453-465. doi: 10.12973/eu-jer.8.2.453

\section{Introduction}

In the era of globalisation, Icelandic society is developing very fast and every year Iceland receives immigrants from all different corners of the world. In 2017, the percentage of residents of foreign background, including first- and secondgeneration immigrants, living in Iceland was 18.8\% (Statistics Iceland, 2017). According to Statistics Iceland, the term first generation immigrant is used to describe a person born abroad with both parents and grandparents born abroad (Statistics Iceland, 2017). With the increasing percentage of immigrants in the country, the number of immigrant students pursuing higher education is constantly growing (Statistics Iceland, 2018). The term immigrant student is applied in this research study to first generation immigrants pursuing tertiary studies in Iceland. The presented paper is based on the results from the first, extensive qualitative research project titled Educational Aspirations, Opportunities and Challenges for Immigrants in University Education in Iceland conducted from 2016 to 2018 in Iceland's three biggest universities. The project was funded by the Icelandic Research Fund (Rannís).

Modern education has become more interactive. Communication and discussions in the classroom play an important role in the educational process (Banks \& Banks, 2010; Smart, Witt, \& Scott, 2012). Multicultural education theory emphasizes the importance of cultural exchange through active communication between teachers and students (Banks \& Banks, 2010; Nieto, 2010). Teachers are encouraged to apply culturally responsive and learner-centred approaches to teaching, which allow students to use their previous experiences and to construct new knowledge during the learning process and thereby become critical thinkers (Brown, 2003; Gay, 2000; Jabbar \& Hardaker, 2013; Smart et al., 2012). Previous research has revealed that creating a rich multicultural environment based on power sharing and mutual respect empowers students and motivates them (Boesch, 2014; Freeman, Anderman, \& Jensen, 2007; Ragnarsdottir \& Blondal, 2014). The above-mentioned reasons show why it is important that universities promote modern teaching methods and encourage teachers to put more emphasis on the learning process and active knowledge construction in the classrooms.

\footnotetext{
* Corresponding author:

Artem Ingmar Benediktsson, Haskoli Islands / University of Iceland, Menntavisindastofnun, Stakkahlid - Hamar, 105 Reykjavik, Iceland. $\bowtie$ artem@hi.is
} 
The primary goal of this study is to explore the participants' experiences of the learning process at Icelandic universities. The main research questions are:

- What are immigrant students' experiences of communication with teachers during the learning process?

- What are immigrant students' reactions to and reflections on the learner-centred approach and culturally responsive teaching methods applied by some teachers?

- What are immigrant students' perspectives on multicultural group work and what challenges do immigrant students encounter during the group work process?

Furthermore, the paper highlights the importance of maintaining an empowering school culture within institutions of higher education, which can contribute to students' positive experiences of the learning environment and encourage their further development.

The methodological limitation of the study is that the results cannot be generalised and applied to all immigrants studying in Icelandic universities. However, generalisation is not the main goal of qualitative research (Lichtman, 2013). Qualitative research aims to explore individual experiences, provide a deeper understanding of the social interactions and give insight into particular cases, which no quantitative research can do.

The study is highly relevant for Icelandic higher education because the number of immigrants pursuing higher education in Iceland is growing every year and the issues that immigrant students might be dealing with on a daily basis are still largely unknown. According to Statistics Iceland, approximately $19 \%$ of all newly registered university students had a foreign background in 2017 (Statistics Iceland, 2018). The present study is also relevant in the European context. According to the Bologna Process Implementation Report (European Commission/EACEA/Eurydice, 2015), immigrants are less likely to enrol in higher education. The newest statistics in Norway show that, while the general number of people pursuing higher education is growing every year, the number of immigrants pursuing higher education is gradually dropping (Tonnessen \& Larsen, 2018). The reasons behind the lower percentage of immigrant students could be a lack of proper educational support and, as a result, a lack of motivation and increasing dropout amongst immigrant students (European Commission/EACEA/Eurydice, 2015; Thang \& Larson, 2010; Wahlgren, Lund, \& Geiger, 2010). This indicates that more research should be conducted to better understand the position of immigrants in higher education in Europe and the challenges that may affect their academic performance and motivation.

\section{Literature Review}

The theoretical framework is based on constructivist theory, which primarily focuses on the learning process and active construction of knowledge through constant development of the student's skills (Brooks \& Brooks, 1993). Constructivist theory places students in the centre of the educational process and emphasises development of each student's professional skills. Special attention is given to students' backgrounds and previous experiences and how they could impact the knowledge constructed during the learning process (Jones \& Brader-Araje, 2002). Furthermore, sharing of experiences and knowledge is highlighted in the constructivist theory, which promotes social interaction, critical thinking and reduction of prejudice (Brooks \& Brooks, 1993; Cornelius-White, 2007; Henson, 2003).

Constructivist theory has similar elements to multicultural education theory, which values every student's previous experiences and emphasises everyone's equal rights and access to education, regardless of ethnicity, race, social status or any other status (Banks \& Banks, 2010). One of the important goals of multicultural education is creating an empowering school culture, where every student feels respected and supported (Banks, 2007). Failure to create an empowering educational environment could affect the motivation of students from various minority groups, including immigrants and lead them to drop out of higher education (Banks, 2007; Nieto, 2010). Multicultural education theory promotes a learner-centred teaching approach, called culturally responsive teaching (Gay, 2000; Villegas \& Lucas, 2002). This approach emphasises encouraging all students to use their previous experiences and cultural backgrounds to construct knowledge (Gay, 2001). A culturally responsive teacher learns about students' previous experiences through active dialogue and prepares curriculum based on students' backgrounds and cultures (Gay, 2000, 2010).

The learner-centred approach has become increasingly prevalent in the field of higher education, which is gradually shifting from a traditional teacher-centred approach that predominantly focuses on students' achievement instead of on the learning process itself (Brown, 2003). Despite the fact that the teacher-centred approach has been actively used throughout centuries, it has some significant weak points, making it irrelevant in modern society. The teacher-centred approach is a passive model, where students are dependent on a teacher who is the primary source of knowledge, which is transmitted to students, who have little chance to criticize it or construct their own knowledge (Grant \& Hill, 2006; Smart et al., 2012).

In contrast to the teacher-centred approach, the learner-centred approach provides students with the opportunity to become critical thinkers and create their own knowledge during active discussions with teachers and peers (Brown, 2003). The role of the teacher is to generate topics of discussions and maintain a productive learning environment that encourages students to learn effectively (Henson, 2003). Previous research has shown a positive impact that the learner-centred approach has on students' learning outcomes (Cornelius-White, 2007). Students who experienced a 
learner-centred approach developed positive relations to peers, became more innovative and learned how to use a wider range of instructional resources, for example, online, multimedia, human, books, etc. (Cornelius-White, 2007; Grant \& Hill, 2006).

Moreover, the learner-centred approach gives students more power to control their educational process and develops their responsibility skills. Power is no longer exclusively in teachers' hands; students are also allowed to decide what they learn and how (Brown, 2003). Sharing power with students and improving their access to managing their learning process can increase equality in the classroom and make every student feel valued (Guy, 1999). Previous studies suggest that adults learn best when they have the opportunity to actively participate in the learning process when they receive practical information and guidelines from the teacher and are granted control over the learning process (Karge, Phillips, Jessee, \& McCabe, 2011; Rubenson, 2011; Wood, 2003).

According to research, positive experiences of personal communications with teachers have also a positive effect on students' academic performance (Boesch, 2014; Ragnarsdottir \& Blondal, 2014). Research conducted by Boesch (2014) revealed that the teachers, through their willingness to create better personal connections with students, improved the dynamics in the classroom and motivated immigrant students. Most students highlighted the fact that teachers' availability and willingness to support students after class hours contributed to their positive experience of the learning process (Boesch, 2014).

The importance of establishing mutual respect and of understanding different students' positions and challenges is often discussed in the field of multicultural education (Banks \& Banks, 2010; Nieto, 2010). However, the results of previous studies emphasize that this does not imply loosening requirements based on student ethnicity (Swaminathan \& Alfred, 2001). Teachers must have equally high academic expectations for all students, regardless of their origins or native languages (Boesch, 2014; Swaminathan \& Alfred, 2001).

Establishing positive and productive peer-to-peer interactions are as important as maintaining positive relations between teachers and students (Jones \& Brader-Araje, 2002; Smart et al., 2012). Earlier research studies have emphasized that group work plays an important role in students' integration into the university environment and develops their communication skills (Hassanien, 2006; Popov et al., 2012). Furthermore, researchers suggest that multicultural group work has a positive effect on students' academic performance, promotes cross-cultural knowledge exchange and empowers students (De Vita, 2002, 2005; Kimmel \& Volet, 2010; Sweeney, Weaven, \& Herington, 2008). Multicultural group work contributes to the elimination of cultural stereotypes and prejudices (De Vita, 2005), an important dimension in multicultural education (Banks, 2007).

Despite all the positive elements connected to group work, different studies have revealed that many students hold negative preconceptions about multicultural group work because they see cultural differences as a barrier instead of advantages (De Vita, 2005; Popov et al., 2012; Sweeney et al., 2008). Popov et al. (2012) studied students' attitudes towards multicultural group work in a university in the Netherlands. The study highlighted some issues connected to multicultural group work. The participants pointed out that difficulties occurred because of some group members' insufficient language skills and general communication problems within the groups, likely related to students' different learning styles, which may come from students' educational cultures (Popov et al., 2012). Students try to avoid multicultural group work by asking teachers to allow them to choose teammates. However, the results of the previous research suggest that teachers should assign group members in order to create more balanced groups and prevent marginalization of some students (De Vita, 2002, 2005). Maiden and Perry (2011) studied issues related to the freeriding phenomenon. Their study revealed that the students appreciate when teachers are observant of the tendencies in the groups, and they use different approaches to deal with free-riders. Among other preconceptions about multicultural group work is that it has a negative effect on the learning outcome and the final grade of the group assignment (De Vita, 2002). The results of previous studies have indicated some tendencies regarding the effect that multicultural group work has on the learning outcome. A study conducted by De Vita (2002) at a British university disproved the misconception that multicultural group work could pull students' average down and emphasized that multicultural group work has positive effects on all members' academic performance. On the other hand, a study conducted by Moore \& Hampton (2015) at an Australian university with diverse student populations revealed that students classified as high-performing with respect to individual assignments received lower grades for group assignments, while mid-performing students received higher grades. However, Moore \& Hampton noted that there was no correlation between students' backgrounds and the differences in grades received for group and individual assignments, which suggests "that individual ability rather than background may be implicated in these differences" (Moore \& Hampton, 2015, p.403).

Previous research has highlighted the teacher's role in multicultural group work and pointed out that proper introduction of goals and helping students to understand the advantages of multicultural group work could eliminate some misconceptions (Forehand, Leigh, Farrell, \& Spurlock, 2016). The assessment method must also be clearly explained, especially when the group is graded as a whole because some students view this assessment method as inequitable (Hassanien, 2006). To avoid negative attitudes towards the assessment methods, some studies suggest 
combining teacher professional assessment and peer assessment through modifying the teacher's grade by the grades allocated by peers (Forehand et al., 2016; Hassanien, 2006).

One of the main goals of multicultural group work is to help students to obtain new knowledge through the process of active communication between group members. The teachers should focus the students' attention on the opportunity to explore new cultures, to learn about group members' different cultural backgrounds and to view their own culture from different perspectives (Kimmel \& Volet, 2010; Sweeney et al., 2008).

The research presented in this article is the first extensive study on immigrant students' experiences of learning environments, teaching methods and group work in Icelandic universities. The results of the study will be discussed in light of the above-listed theories and related to previous research conducted in different countries.

\section{Methodology}

An extensive qualitative study was conducted from 2016 to 2018 in three Icelandic universities: University of Iceland, University of Akureyri and Reykjavik University. The researchers' aim was to select participants through maximal variation sampling, based on characteristics such as age, first language, country of origin, field of studies and Icelandic language proficiency. The registrars of the targeted universities were asked to provide information about students of foreign origin. Later, a snowball sampling method of recruiting participants was applied (Flick, 2009; Lichtman, 2013). A total of 41 students (12 male and 29 female) who have studied at the undergraduate level for at least one year were recruited to participate in the research. The participants' ages ranged from 20 to 52 years old. They come from 23 different countries in Europe, Asia, and North and South America and have lived in Iceland from 2 to 18 years.

The Icelandic Data Protection Authority was informed about the research. All privacy considerations were in compliance with Icelandic law nr.77/2000 and the Ethics Committee standards for qualitative research.

The study was split into three phases: focus group interviews (conducted in September 2016 - January 2017); individual, in-depth interviews (conducted in September 2016 - May 2017); and repeated focus group interviews (conducted February 2018 - April 2018). Focus group interviews were conducted through a directive interviewing approach, where the researcher played a directive role by asking questions and leading the group towards specific topics (Lichtman, 2013). The goal of the focus group interviews was to create a discussion about the chosen topics of the research between participants and observe their interactions around the research topic (Bender, 2003; Lichtman, 2013). The results of the focus group interviews were used to create an interview guide for the individual, in-depth interviews with the same participants. The individual interviews were semi-structured, which gave the participants room to discuss issues not covered by the interview guide (Brinkmann \& Kvale, 2009; Flick, 2009). The researchers decided to meet the participants again nine months after the last individual interview was conducted. The main purpose was to discuss the participants' educational progress and compare their current experiences of the learning environment to the experiences that they shared earlier. All interviews were conducted in Icelandic and/or English.

The individual interview guide included a variety of questions related to the participants' experiences of the learning environments, teaching methods, communication with peers and teachers as well as background questions and questions about formal and informal support received during their studies. The average length of the interviews was 47 minutes. The interview questions that are related to this paper's main goal are presented below:

- What can you tell about your experiences of being an immigrant student at the university?

- What can you tell about the relations between the students in the classroom?

- How did the teachers encourage students to get to know each other?

- What is your experience of group work?

○ How were the members of the groups assigned? (teacher assigned or students chose themselves)

- What are your experiences of communication in the groups?

- What language did you use during the group work?

- How was the workload divided between members?

- What can you tell about the assessment of the group work?

- What can you tell about your relations with the teachers?

- Have you ever personally contacted a teacher? (Before or after the class start)

- What can you tell about your experiences of communication with teachers?

- If the courses were taught in Icelandic: Did the teachers ask whether there were any students who could not understand Icelandic?

- What did the teacher do to resolve language related issues?

- What do you think about the teaching methods? What teaching methods did the teachers apply?

○ Did the teacher use examples to explain things? Were the examples good?

- Could you use your previous knowledge and experiences in your study? If yes, please explain how.

- Do you have anything else that you would like to share with us regarding your experiences at the university? 
Processing and analysing the collected data started immediately after the first interview was transcribed (Creswell, 2008). The total amount of data collected during the interviews exceeded 1500 pages. The data was analysed using thematic analysis approach (Braun \& Clarke, 2013; Lichtman, 2013). Special analytical software, Atlas.ti, was used to analyse all interviews. Raw data from the transcriptions was coded and constantly compared using the Atlas.ti software. Codes were assembled in categories, and at the final stage, main themes were created out of the categories. These themes are presented below including the key codes, which support the themes.

- Learner-centred approach and the importance of communication

○ Class discussions

- Communication with teachers

- Critical thinking

- Negative experiences of communication

- Power sharing

○ Usage of Icelandic/English during the learning process

- Advantages of culturally responsive teaching

○ Culturally responsive assessment

- Culturally responsive teaching

○ Freedom of expressions and critical thinking

$\circ \quad$ Knowledge / Experiences sharing between teachers and students

- Multicultural group work as an opportunity to share knowledge across cultures

$\circ$ Assigning members of the groups

- Free-riding

- Group assessment

- Knowledge sharing within the groups

$\circ \quad$ Language related issues

- Misunderstanding of the purpose of group work

○ Negative experiences of group work

- Positive experiences of group work

- Role of teachers in group work

- Teachers' low expectations based on student background

○ Lowering the requirements

- Misinterpretations of immigrant students' needs

○ Teachers attitudes towards immigrant students

- Movement towards empowering school culture

- Autonomy and emancipation

- Equality and sense of belonging in the classroom

○ Positive learning environment

In the next chapter, the findings, including quotations related to the themes and the key codes will be presented and analysed in the light of the relevant theories and results from earlier research studies.

\section{Findings}

Five main themes were derived from the interviews with the participants. The first theme covers the participants' experiences of communication with teachers during the learning process and reveals the importance of applying a learner-centred approach in the multicultural classroom. The second theme presents the participants' reflections on culturally responsive teaching and highlights the advantages of it. The third theme reveals the participants' perspectives on multicultural group work. The fourth theme exposes issues related to teachers' lower expectations for immigrant students. The fifth theme presents the participants' experiences of the empowering school culture developing in Icelandic universities. All quotations derived from the interviews that were conducted in English are presented in their original form. Quotations from the interviews that were conducted in Icelandic have been translated by the authors from Icelandic into English.

\section{"The class became livelier because there was more communication"}

\section{Learner-centred approach and the importance of communication}

Modern education theorists emphasise the significance of a learner-centred approach and previous research shows the positive effect that such an approach has on students' academic performance and general experiences of the learning process (Brown, 2003; Cornelius-White, 2007; Smart et al., 2012; Webber, 2012). According to the results of the interviews with the participants in the presented study, there is some evidence of learner-centred approaches in learning environments in Icelandic universities. When it comes to power sharing in the classroom, the majority of teachers are open for discussions and the communication with them was based on mutual trust. Students revealed that most of the teachers were open to having an active dialogue with students and putting emphasis on equality in the 
classroom, which are important elements of the learner-centred approach and are especially valued by the theorists of multicultural education (Banks \& Banks, 2010; Brown, 2003; Freeman et al., 2007; Guy, 1999).

The participants emphasised the importance of teachers promoting active interaction in the classroom. Several distance learning students who participated in the research revealed that they found it very helpful and encouraging when teachers fostered interaction between students during the sessions for the distance learning students.

They bring discussions to the students. These are the best teachers that actually promote some interaction. Even if we are distance learners, they have found ways to promote interaction.

Previous research revealed the significance of active communication during the learning process to further contribute to the students' integration and sense of belonging in the university environment (Freeman et al., 2007; Ragnarsdottir \& Blondal, 2014).

The participants stated that the majority of teachers were easily accessible, and they were interested in getting feedback from the students. Several students mentioned that it was unusual for them to call their teachers by their first names without adding any titles when referring to a teacher. The participants valued the atmosphere of equality and trust created in the classroom and concluded that it had a positive impact on their experiences of the learning environment.

Teachers are really helpful. You know, they are not trying to have levels or status. It is always kind of the same level everyone [...] We have a relationship like a friendship.

Furthermore, the participants highly valued the importance of teachers providing necessary tools and guidelines to pursue education and allowing students to work independently. Teachers' role shifted from being merely a source of knowledge to becoming contributors to students' development.

Teachers expect students to be much more independent [...] The teacher is presenting a class and has the tools to present for the students. But students are pretty much expected to work on their own.

According to the participants, some teachers are following a teacher-centred approach and still put an extensive focus on students' achievement and do not encourage active knowledge construction in the classroom. In those cases, the participants' experiences were mostly negative, and they even concluded that this kind of approach has little to do with teaching. In one of the interviews, the participant, who studied psychology, compared two different teaching methods and shared her experiences of them.

Basically, they are not exactly teaching per se. They have translated the book, the chapter of the book that we are studying. They have put it in a Power Point presentation, and so it is a summarized translation of the book. And sometimes teachers are basically reading the slides so there is not much teaching in it. There is not going to be anything extra [...] But not all the teachers. Some of them bring extra materials besides the books [...] Sometimes we have sessions via Skype. When we have the teaching sessions they bring discussions to the students.

This particular participant's experiences confirm the significance of bringing active discussions into the classroom and applying a learner-centred approach. According to research and theory, this approach promotes critical thinking and knowledge construction during the learning process (Brown, 2003; Cornelius-White, 2007; Henson, 2003).

During one of the group interviews, an interesting case was described by a participant who is currently studying foreign languages. A teacher noticed that several immigrant students did not participate in the class discussions. He found out that the reason was the students' limited Icelandic language skills. In order to activate those students, the teacher suggested carrying out the discussion in English instead of Icelandic, a change that gave good results.

There were one or two classes that ended up being in English. And the class became livelier because there was more communication. People started to interact with the teacher. They started answering questions and discussing things, which really did not happen when class was taught in Icelandic, because then there was like one or two questions and teacher just talking all the time.

In the above-mentioned case, the teacher did not merely care about following the teaching plan. He observed the tendencies in the classroom and made a step towards improving the learning process by allowing all students to participate in the class discussions. Different studies showed that communication in the classroom during the learning process is very important for creating a productive learning environment (Rubenson, 2011; Smart et al., 2012). However, students' limited language skills and lack of support could become an obstacle in communication with peers and teachers (Boesch, 2014; Erisman \& Looney, 2007). That is why it is important to provide appropriate support and apply an individual approach to every student in the classroom in order to ensure a positive learning experience and active engagement in the learning process.

The results of this study indicate that the participants valued those teachers who encouraged them to use their previous knowledge and experiences throughout the learning process. During the interviews, the researchers were 
highly interested in analysing the participants' reactions to and reflections on culturally responsive teaching methods, which are an important dimension of multicultural education. The results related to the experiences of culturally responsive teaching methods presented in the next section.

"You could share your experiences and it was just interesting to speak to everyone"

\section{Advantages of culturally responsive teaching}

Culturally responsive teaching methods are designed to incorporate students' backgrounds and knowledge into their learning processes (Gay, 2000; Villegas \& Lucas, 2002). In the course of the interviews, the participants were asked if they could use their backgrounds in the learning process and whether teachers encouraged them to do so. Relatively few participants experienced culturally responsive teaching.

Several participants revealed that some teachers were trying to activate immigrant students by integrating content from students' home countries into curriculum and by encouraging students to relate new knowledge to their previous experiences. These teaching techniques were appreciated by the participants, and they expressed positive attitudes towards the courses where similar techniques were applied.

They [teachers] are the best! I mean they are really good, and the communication was really friendly. And teachers allowed us to be ourselves and I really enjoyed it.

In the School of Education, it is very personal ... You could share your experiences, and it was just interesting to speak to everyone.

During the analytical process, the researchers noticed a tendency that the vast majority of the participants who experienced culturally responsive teaching were students at the School of Education at the University of Iceland. This tendency could be explained by the current emphasis on the implementation of culturally responsive teaching methods at the School of Education. A special programme named International Studies in Education has been recently developed at the School of Education (Books, Ragnarsdottir, Jonsson, \& Macdonald, 2011; University of Iceland, 2018). The programme particularly focuses on international students and students whose native language is not Icelandic, and the developers of the programme emphasized the importance of multicultural education and culturally responsive teaching methods (Books et al., 2011). Earlier research on students' experiences of the teaching methods confirmed that the International Studies in Education programme empowered students and gave them the confidence to pursue further studies (Ragnarsdottir \& Blondal, 2014).

A current student at the School of Education, who formerly studied at the School of Humanities, revealed that the differences between the schools were significant.

There is a huge difference. At the teaching department, you can feel that it is warmer, like all the activities are very nicely combined. So, I don't know, but I felt the difference.

The same participant later provided more details about why his experience of the learning environment at the School of Education was so positive.

It was just an enjoyment. We were always discussing things and talking about them. Always. It was not just some academic studies, it was an experience. And we were always listening about different opinions and discussing what we have learned.

This student is talking about fundamental dimensions of culturally responsive teaching, open discussion and knowledge exchange in the classroom (Gay, 2000; Nieto, 2010). This also corresponds to the main principles of the learner-centred approach, where discussions and knowledge construction are in the centre of the learning process (Brown, 2003; Henson, 2003).

A participant who studied geology compared two different teaching styles that she experienced and gave her preferences for teaching methods where the teacher shared his or her own personal experiences with the students and related them to the subject.

I am keener on teachers who are not just reading slides, but who speak about something interesting, which is easy to remember. Not just reading the slides. The teachers who tell about their experiences.

The participant emphasizes the importance of mutual knowledge exchange, where both students and teachers share life experiences with each other. By providing examples from his or her personal experience, the teacher is not merely making the teaching more interesting, but he or she encourages the students to do the same.

Previous research has highlighted the importance of applying culturally responsive assessment methods in a multicultural classroom (Slee, 2010). A participant who studies biotechnology shared his experiences of culturally responsive assessment. 
I see, for example, that teachers are trying to fish for strengths and weaknesses from the students. And I see there is at least one teacher who says that I am good in something particular, and I get a chance to develop me further. And he points out my weaknesses and he says that I should try more.

The participant is talking about teachers who analyse students' educational performance and emphasize their strengths while encouraging them to develop further and pointing out places for improvement. This corresponds to culturally responsive assessment methods that prove to be useful in multicultural learning environments (Slee, 2010).

Culturally responsive teaching involves a lot of communication in the classroom. In order to activate students and provide an opportunity to share knowledge, group work is often recommended during the learning process. However, several research studies revealed that students' experiences of group work are different and range from being highly positive to negative (De Vita, 2005; Forehand et al., 2016; Popov et al., 2012).

"It enriches you as a person"

Multicultural group work as an opportunity to share knowledge across cultures

During the interviews, the question of group work was one of the most discussed and the participants' experiences of multicultural group work and communication with peers were very different.

Earlier research studies have highlighted the importance of multicultural group work in classrooms with diverse student populations (Popov et al., 2012; Sweeney et al., 2008). Multicultural group work encourages students to enter into direct dialogue with their peers and helps to reduce existing cultural prejudices in a classroom. A participant who studied international relations revealed that it was a positive and beneficial experience to work with students from different countries.

It was interesting and fun sometimes. And useful to follow different opinions from the American school, German, Russian and even, you know, Nordic and Chinese students. It was something very beneficial.

Another participant who studied foreign languages also considered multicultural group work being useful. Furthermore, he concluded that group work was effective for learning how to work together with a diverse group of people and adapt to different situations.

I think it [multicultural group work] is very interesting because it enriches you as a person. And also, to get to know how to expand your limits and go forward as well.

There were several participants who preferred working with Icelandic students rather than in multicultural groups because the final reports from the group work had to be written in Icelandic. Some participants saw an advantage in working with Icelanders who could do the written part while they would contribute orally. A participant who studied biology clearly explained the advantages of working in groups with Icelandic peers. He also mentioned that his Icelandic peers were generally open to speaking English during the group discussions.

We sit together and it's really up to my student mates what language are we speaking, but they are usually even more open than the teachers to English. And then they write in Icelandic the report, and you know, I just give them verbal input on what my opinion is, and they just translate it into Icelandic.

A participant who currently studies business administration discussed some issues that might occur in Icelandic settings around multicultural group work. He felt that some members of the group could pull the whole group down because of a lack of language skills in academic Icelandic. His worry was that the workload in a multicultural group work might be divided unevenly and that Icelandic students had to do writing and editing work for their non-Icelandic peers.

If I have to do group work, then of course is difficult because sometimes people [peers] have to read over what I did. So, I always try to compensate in other areas. But I actually experience sometimes, there are few Polish people here who are studying with me, and they always ask if I wanted to be in the group with them. And in the beginning, I always did it. But then I started turning people down because it's too much, it's too difficult for other Icelanders to have many foreigners in the same group if the assignment was done in Icelandic. So, that was probably the most difficult thing.

While the participant's fears may be understandable, preceding research has emphasized the fact that multicultural group work does not have a negative impact on students' performance, and the assumption that multicultural group work could pull down individual members' academic scores was not confirmed (De Vita, 2002).

In the above quotation, the participant highlights the fact that it was difficult for him to turn people down based on their language skills or origins. The solution to this problem was suggested in previous studies, where the emphasis was put on the teacher's role in reducing such problems by assigning people into groups and creating more balanced groups rather than allowing students to choose members of a group (De Vita, 2002, 2005). Another participant who studies business administration revealed that she understands the advantages of members being assigned to the groups and saw it as an opportunity to prepare for future work. 
Teachers do not want to allow us to choose [members for the group work]. They want to assign groups, because they are just preparing us for future work, because you won't get to choose who you work with when you are working in a company.

A different issue that several participants became aware of is free-riding within groups and, as a result, a lower group grade.

I am generally satisfied with the grades which I get, but sometimes it is just bad, when some members are just riders. Do you understand? They are in the group but don't do anything but still get the same grade as a person who have done a lot [...] I think it is unfair that this member gets the same grade as me. And it is pulling the grade down.

Earlier research studies suggest different ways of dealing with free-riding within the groups and reducing student dissatisfaction with grades (Forehand et al., 2016; Hassanien, 2006; Maiden \& Perry, 2011). It is suggested, among other things, that teachers develop more advanced assessment methods and combine peer assessment with teacher assessment. Peer assessment is also recommended as an assessment method when applying a learner-centred approach to teaching, as this type of evaluation triggers active discussions and communication within the groups (Brown, 2003; Webber, 2012).

During one of the group interviews, the researchers became aware that some participants lack understanding about the purpose of group work, which later resulted in the participants' dissatisfaction with the learning process and the learning outcome. A participant who studies Icelandic as a second language shared his experiences of group work, while several other participants who took part in the same group interview agreed with him.

Maybe it is just my problem, but I hate group assignments [Researcher note: Several other participants nod their agreement and one of them says, Yes, yes] Because if I make mistakes, they are just my mistakes, and I don't want to think that there are other people in the group. It makes me stressed. I just don't understand why we are doing so many group assignments, because it is like a group knowledge, not what I have learned.

In this case, the issues could probably have been solved at an early stage if the teacher clearly introduced the purposes of group work and explained the advantages of multicultural group work. This particular student does not understand how the group work can contribute to his education and he does not see the benefits of the process of knowledge construction within the group. Different research studies highlighted that proper introduction, dialogue with students and more advanced assessment methods could eliminate some issues and misconceptions related to multicultural group work (Forehand et al., 2016; Hassanien, 2006).

Although the majority of the experiences shared by the participants were positive or neutral, some of their experiences were negative, and the participants wished that universities could improve in some areas. One issue described by several participants stood out and will be discussed in the next section.

"I think, she approached us as if we were children"

\section{Teachers' low expectations based on student background}

Several participants revealed that they wished that some teachers would change their attitudes towards immigrant students and did not evaluate academic competences solely based on the students' origins or language skills. The participants described situations when teachers had lower expectations for immigrant students and did not treat them equally.

In our field, they [teachers] were not really qualified. They treated us very positively, like their sons and daughters, but it was a bit of a kindergarten.

The teacher didn't teach us very well. I think, she kind of approached us as if we were children.

The participants understood that the teachers, by approaching them differently, were trying to help, but this particular approach did not work well. Theorists and previous research in the field of multicultural education underline the fact that understanding students' needs and being flexible without loosening the requirements based on students' ethnicity or background is very important in the multicultural learning environment (Banks \& Banks, 2010; Nieto, 2010; Swaminathan \& Alfred, 2001). Teachers' misinterpretation of immigrant students' needs resulted in the participants' negative experiences of the learning process and communication with those teachers.

Although the participants experienced challenges related to some teachers' misconceptions, they admitted that Icelandic university culture is positive and open to immigrant students.

"The university gave me emancipation and ambition to think freely" 
The study revealed that the environments at the three target universities are modern and open for immigrant students. The participants stated that the majority of teachers were willing to provide extra support and were generally open for discussion of any issues that occur during the learning process.

Creating an empowering school culture, where every student feels valued, where knowledge is constructed through active dialogue, and where the whole system is based on equity pedagogy and an individual approach for every student is a significant goal of multicultural education (Banks \& Banks, 2010). These factors are also included in constructivist education theory, which gives priority to students' learning experiences and development as critical thinkers (Jones \& Brader-Araje, 2002). The results of the presented research indicate that the participants have already experienced some of the dimensions of multicultural education and that their experiences are mainly positive. A participant who studies education sciences and a participant who studies sociology both reflected on the question of autonomy and independence, which they enjoyed during their studies. They appreciated teachers allowing them to be critical thinkers and encouraging them to construct their own knowledge during the education process.

I am very happy with the international program because it gives me more autonomy in what I want to study.

I like that you are independent, and you are free to innovate your own thoughts, create your own identity instead of being a robot in the class. So, I really like especially this Icelandic way of teaching.

A participant who studies foreign languages and a participant who studies biology had similarly positive experiences of the learning environment and revealed that they enjoyed the equality and friendly atmosphere. They mentioned that the university became their home away from home.

In our department [Faculty of Languages and Cultures] it's kind of a small family you know. So, we just invite each other for dinner eating outside, that kind of things, which is quite nice here.

I really felt at home in Askja [School of Engineering and Natural Sciences]. I very quickly found my own place, where I do things and yeah, I usually feel really comfortable there generally, I like going there.

The students who participated in the research studies conducted by Boesch (2014) and Freeman et al. (2007) also underlined how good communication with teachers and a school environment based on equality and trust can have a positive impact on students' sense of belonging and create a positive learning environment.

A participant who studied both Icelandic as a second language and international relations summarized his positive experiences of the learning process and concluded that the education empowered him. During the learning process, he learned how to be an independent thinker.

I like that the university gave me emancipation and ambition to think freely. And this is the place where I got an encouragement to be a free thinker, that's the most important thing.

The results of the current research revealed that, despite some challenges the participants faced during their learning process, their overall experiences are positive. The learning environments at Icelandic universities are considered by the majority of the participants being open and free from prejudice.

\section{Conclusion}

The analysis of the findings shows that many participants have had similar experiences of the learning process, which may indicate some common tendencies and challenges that other students with similar characteristics face during their studies. Based on the data analysis, several themes related to the research goals developed from the interviews. The primary focus of the study was on exploring the participants' experiences of communication with teachers during the learning process, culturally responsive teaching methods and a learner-centred approach. Furthermore, the participants' perspectives on multicultural group work were analysed as well as challenges related to group work.

The majority of the participants stressed the fact that their experiences of communication with teachers were generally positive. Teachers were easily accessible, and they encouraged students to think critically. The analysis of the interviews revealed that many teachers in Icelandic universities apply a learner-centred approach, and according to the participants' experiences, this approach had a positive effect on their academic performance and triggered discussions in the classroom. The participants valued teachers who were trying to provide every student with appropriate educational support and to allow everyone to follow his or her own learning style rather than seeking one teaching method that would suit all. This corresponds to the constructivist theory, which put emphasises a learner-centred approach and highlights the importance of allowing students to take an active part in the learning process, as opposed to passively following teachers' instructions (Henson, 2003; Jones \& Brader-Araje, 2002). In contrast to the positive experiences of the learner-centred approach, the participants' perspectives on the teacher-centred approach were mostly negative. They criticised those teachers who put an extensive focus on students' achievement rather than on the learning process. 
The participants appreciated it when teachers allowed them to use their cultural backgrounds and previous experiences during the learning process. Although some teachers apply several, single dimensions of culturally responsive teaching, such as content integration and prejudice reduction through open discussions in the classroom, the analysis of the interviews revealed that culturally responsive teaching is still an uncommon phenomenon in the Icelandic universities and that relatively few teachers apply these teaching methods. The participants' experiences of culturally responsive teaching are exclusively positive, and they highlighted the positive impact it had on their sense of belonging in the learning environment.

Despite all the positive elements related to group work, the participants' experiences ranged from being highly positive to distinctly negative. Some participants valued group work and saw it as an opportunity to exchange knowledge and learn about different group members' experiences. They also approached group work from the point of view of it preparing them for future jobs, as the majority of modern professions require at least some amount of group work. The participants whose experiences of group work were negative showed signs of a general misunderstanding of the purpose of group work or had some misconceptions related to the process itself, such as a misguided belief that multicultural group work could pull down individual members' academic scores. Previous research in the field of multicultural group work has indicated that, in most cases, these issues and misconceptions could be eliminated by properly introducing the purpose of group work to students and applying more advanced assessment methods (De Vita, 2002, 2005; Hassanien, 2006; Popov et al., 2012).

During the process of analysis, several participants pointed out the significant issue of some teachers' having low expectations towards immigrant students based on their origins and skills in Icelandic. Earlier research studies have underlined the importance of treating all students equally and having high academic expectations for every student regardless of his or her cultural or ethnic background (Banks \& Banks, 2010; Nieto, 2010; Swaminathan \& Alfred, 2001). Several participants' negative experiences revealed that lowering the expectations and treating some students like children were not the ways that teachers should have chosen.

Regardless of the highlighted issues, the participants' overall experiences of the learning environments in the three Icelandic universities in this study were mostly positive. Several participants emphasised the empowering effect that university education had on them. They revealed that their university or department is a place where they feel valued and where they have an opportunity to develop their strengths and become independent thinkers.

\section{References}

Banks, J. A. (2007). Multicultural education: Characteristics and goals. In J. A. Banks \& C. A. M. Banks (Eds.), Multicultural education: Issues and perspectives (2. ed., pp. 3-30). Hoboken, NJ: Wiley.

Banks, J. A., \& Banks, C. A. M. (Eds.) (2010). Multicultural education: Issues and perspectives (7th ed.). Hoboken, NJ: Wiley.

Bender, S. S. (2003). Rynihopar [Focus groups]. In S. Halldorsdottir \& K. Kristjansson (Eds.), Handbok i adferdafrædi og rannsoknum i heilbrigdisvisindum [Handbook of methodology and research in health sciences] (pp. 85-99). Akureyri, Iceland: University of Akureyri.

Boesch, B. (2014). The importance of the professor in college classroom climate for immigrant students. College Quarterly, 17(4).

Books, S., Ragnarsdottir, H., Jonsson, O. P., \& Macdonald, A. (2011). A university program with "the whole world as a focus": An Icelandic response to globalization. Innovative Higher Education, 36(2), 125-139. doi: 10.1007/s10755010-9163-7

Braun, V., \& Clarke, V. (2013). Successful Qualitative Research : A Practical Guide for Beginners. London, UK: Sage.

Brinkmann, S., \& Kvale, S. (2009). InterViews: Learning the craft of qualitative research interviewing (2. ed.). Thousand Oaks, CA: Sage.

Brooks, J. G., \& Brooks, M. G. (1993). The case for the constructivist classrooms. Alexandria, VA: ASCD.

Brown, K. L. (2003). From teacher-centered to learner-centered curriculum: Improving learning in diverse classrooms. Education, 124(1), 49-54.

Cornelius-White, J. (2007). Learner-centered teacher-student relationships are effective: A meta-analysis. Review of Educational Research, 77(1), 113-143. doi: 10.3102/003465430298563

Creswell, J. W. (2008). Educational research: Planning, conducting, and evaluating qualitative and qualitative research. Upper Saddle River, NJ: Pearson.

De Vita, G. (2002). Does assessed multicultural group work really pull UK students' average down? Assessment \& Evaluation in Higher Education, 27(2), 153-161. doi: 10.1080/02602930220128724 
De Vita, G. (2005). Fostering intercultural learning through multicultural group work. In J. Carroll \& J. Ryan (Eds.), Teaching international students: Improving learning for all (pp. 75-83). New York, NY: Routledge.

Erisman, W., \& Looney, S. (2007). Opening the door to the American dream: Increasing higher education access and success for immigrants. Washington, DC: Institute for Higher Education Policy.

European Commission/EACEA/Eurydice. (2015). The European Higher Education Area in 2015: Bologna Process Implementation Report. Luxembourg, Luxembourg: Publications Office of the European Union.

Flick, U. (2009). An introduction to qualitative research (4th ed.). London: Sage.

Forehand, J. W., Leigh, K. H., Farrell, R. G., \& Spurlock, A. Y. (2016). Social dynamics in group work. Teaching and Learning in Nursing, 11(2), 62-66. doi: 10.1016/j.teln.2015.12.007

Freeman, T. M., Anderman, L. H., \& Jensen, J. M. (2007). Sense of belonging in college freshmen at the classroom and campus levels. The Journal of Experimental Education, 75(3), 203-220. doi: 10.3200/JEXE.75.3.203-220

Gay, G. (2000). Culturally responsive teaching: Theory, research and practice. New York, NY: Teachers College Press.

Gay, G. (2001). Preparing for culturally responsive teaching. Journal of Teacher Education, 53(2), 106-116. doi: $10.1177 / 0022487102053002003$

Gay, G. (2010). Acting on beliefs in teacher education for cultural diversity. Journal of Teacher Education, 61(1-2), 143152. doi: $10.1177 / 0022487109347320$

Grant, M. M., \& Hill, J. R. (2006). Weighing the rewards with the risks? Implementing student-centered pedagogy within high-stakes testing. In R. Lambert \& C. McCarthy (Eds.), Understanding teacher stress in the age of accountability (pp. 19-42). Greenwich, CT: Information Age Publishing.

Guy, T. C. (1999). Culture as context for adult education: The need for culturally relevant adult education. New directions for adult and continuing education (82), 5-18. doi: 10.1002/ace.8201

Hassanien, A. (2006). Student experience of group work and group assessment in higher education. Journal of teaching in travel \& tourism, 6(1), 17-39. doi: 10.1300/J172v06n01_02

Henson, K. T. (2003). Foundations for learner-centered education: A knowledge base. Education, 124(1), 5-16.

Jabbar, A., \& Hardaker, G. (2013). The role of culturally responsive teaching for supporting ethnic diversity in British University Business Schools. Teaching in Higher Education, 18(3), 272-284. doi: 10.1080/13562517.2012.725221

Jones, M. G., \& Brader-Araje, L. (2002). The impact of constructivism on education: Language, discourse, and meaning. American Communication Journal, 5(3), 1-10.

Karge, B. D., Phillips, K. M., Jessee, T., \& McCabe, M. (2011). Effective strategies for engaging adult learners. Journal of College Teaching \& Learning, 8(12), 53-56.

Kimmel, K., \& Volet, S. (2010). Significance of context in university students' (meta) cognitions related to group work: A multi-layered, multi-dimensional and cultural approach. Learning and Instruction, 20(6), 449-464. doi: 10.1016/j.learninstruc.2009.05.004

Lichtman, M. (2013). Qualitative Research in Education (3rd ed.). Thousand Oaks, CA: SAGE.

Maiden, B., \& Perry, B. (2011). Dealing with free-riders in assessed group work: results from a study at a UK university. Evaluation in Higher Education, 36(4), 451-464. doi: 10.1080/02602930903429302

Moore, P., \& Hampton, G. (2015). 'It's a bit of a generalisation, but ...': participant perspectives on in tercultural group assessment in higher education. Assessment \& Evaluation in Higher Education, 40(3), 390-406. doi: 10.1080/02602938.2014.919437

Nieto, S. (2010). The light in their eyes: Creating multicultural learning communities (10th Anniversary ed.). New York, NY: Teachers College Press.

Popov, V., Brinkman, D., Biemans, H. J. A., Mulder, M., Kuznetsov, A., \& Noroozi, O. (2012). Multicultural student group work in higher education: An explorative case study on challenges as perceived by students. International Journal of Intercultural Relations, 36(2), 302-317. doi: 10.1016/j.ijintrel.2011.09.004

Ragnarsdottir, H., \& Blondal, H. (2014). Fjolmenningarlegt namssamfelag: Reynsla nemenda af albjodlegu nami í menntunarfrædi vid Haskola Islands [Multicultural learning community: The experiences of students in the International Studies in Education programme at the University of Iceland]. Uppeldi og menntun [Icelandic Journal of Education], 23(1), 27-45.

Rubenson, K. (2011). Adult Learning and Education. Oxford, UK: Academic Press. 
Slee, J. (2010). A systemic approach to culturally responsive assessment practices and evaluation. Higher Education Quarterly, 64(3), 246-260. doi: 10.1111/j.1468-2273.2010.00464.x

Smart, K. L., Witt, C., \& Scott, J. P. (2012). Toward learner-centered teaching: An inductive approach. Business and Professional Communication Quarterly, 75(4), 392 - 403. doi: 10.1177/1080569912459752

Statistics Iceland. (2017). Innflytjendum heldur afram ad fjolga [Number of immigrants keeps increasing]. Retrieved from https://www.hagstofa.is/utgafur/frettasafn/mannfjoldi/mannfjoldi-eftir-bakgrunni-2017/

Statistics Iceland. (2018). Fjoldi nynema a haskolastigi hefur tvofaldast a tuttugu arum [Number of new university students doubled during past twenty years]. Retrieved from https://hagstofa.is/utgafur/frettasafn/menntun/nynemar-i-haskolum-2010-2017/

Swaminathan, R., \& Alfred, M. V. (2001). Strangers in the mirror: Immigrant students in the higher education classroom. Adult learning, 13(1), 29-32. doi: 10.1177/104515950101200408

Sweeney, A., Weaven, S., \& Herington, C. (2008). Multicultural influences on group learning: A qualitative higher education study. Assessment \& Evaluation in Higher Education, 33(2), 119-132. doi: 10.1080/02602930601125665

Thang, P. O., \& Larson, M. (2010). Integration genom vuxenutbildning och vidareutbildning. Landrapport Sverige [Integration through adult education and further education. Country report Sweden]. Copenhagen, Denmark: Nordisk Ministerrad.

Tonnessen, E., \& Larsen, H. (2018). Andelen av innvandrere som tar hoyere utdanning gar ned [The percentage of immigrants who pursue higher education goes down]. Khrono.no. Retrieved from https://khrono.no/ntnu-uiounik5/andelen-av-innvandrere-som-tar-hoyere-utdanning-gar-ned/217837

University of Iceland. (2018). International Studies in Education. Retrieved from https://english.hi.is/international_studies_in_education

Villegas, A. M., \& Lucas, T. (2002). Preparing culturally responsive teachers rethinking the curriculum. Journal of Teacher Education, 53(1), 20-32. doi: 10.1177/0022487102053001003

Wahlgren, B., Lund, K., \& Geiger, T. (2010). Integration gennem voksen- og efteruddannelse [Integration through adult and further education]. Copenhagen, Denmark: Nordisk Ministerrad.

Webber, K. L. (2012). The use of learner-centered assessment in US colleges and universities. Research in Higher Education, 53(2), 201-228. doi: 10.1007/s11162-011-9245-0

Wood, C. M. (2003). The effects of creating psychological ownership among students in group projects. Journal of Marketing Education, 25(3), 240-249.doi: 10.1177/0273475303257553 